\title{
Patrimonio nuclear del sur de España. Diagnóstico y propuestas
}

\author{
Nuclear heritage of the south of Spain. Diagnosis and proposals \\ Juan Antonio Muñoz-Castillo \\ juanantonio.munoz@iesaverroes.org @ 0000-0002-9755-5541 \\ Departamento de Geografía e Historia. Instituto de Educación Secundaria "Averroes" de Córdoba. \\ C/ Motril, s/n. 14013 Córdoba, España \\ Jorge Olcina-Cantos \\ jorge.olcina@ua.es @ 0000-0002-4846-8126 \\ Departamento de Análisis Geográfico Regional y Geografía Física. Universidad de Alicante. \\ Campus de San Vicente del Raspeig s/n. 03690 Alicante, España
}

\section{INFO ARTÍCULO}

Enviado: 21/10/2021

Revisado: 06/12/2021

Aceptado: 24/12/2021

PALABRAS CLAVE

Patrimonio nuclear

Andalucía

Badajoz

Uranio

Residuos radiactivos

\section{KEYWORDS}

Nuclear heritage

Andalucía

Badajoz

Uranium

Radioactive wastes

\begin{abstract}
RESUMEN
El presente trabajo es una puesta al día del patrimonio nuclear existente en el sur de España. Las antiguas minas de uranio, las fábricas de combustible nuclear, los almacenes de residuos nucleares o los lugares afectados por accidentes nucleares tienen un conjunto de posibilidades por encima de su relación con la actividad del uranio. Se analiza y valora el estado de las instalaciones nucleares existentes en el sur de España que forman un conjunto patrimonial que merece atención institucional y puede tener oportunidades para su trasformación en recurso de aprovechamiento docente o turístico. Del análisis detallado de cada elemento del objeto de estudio, se ha pasado a establecer el diagrama de fortalezas y debilidades del conjunto. El patrimonio nuclear analizado sufre una estigmatización que se debe revertir a partir de una serie de acciones conducentes al desarrollo de las localidades afectadas, en una serie de acciones conducentes de modo sostenible a integrarles en sus entornos regionales.
\end{abstract}

\begin{abstract}
This paper is an update of the existing nuclear heritage in southern Spain. Old uranium mines, nuclear fuel factories, nuclear waste warehouses or places affected by nuclear accidents have a set of possibilities beyond their relation to uranium activity. The state of existing nuclear facilities in southern Spain, which form a heritage complex that deserves institutional attention and may have opportunities for its transformation into a resource for educational or tourist use, is analyzed and valued. From the detailed analysis of each element to the object of study, the diagram of strengths and weaknesses of the whole has been established. This suffers a certain stigmatization that should be reverted in a series of actions conducive in a sustainable way to comprehensiveness in their regional environments.
\end{abstract}




\section{INTRODUCCIÓN}

El patrimonio nuclear puede entenderse como el "conjunto formado por las infraestructuras mineras de producción y transformación de minerales de uranio, así como la obtención de energía nuclear, junto con aquellas zonas destinadas a la gestión de sus residuos, y las que, por cualquier circunstancia anómala, se hayan visto afectadas por el uranio, sus derivados y la radiactividad de una u otra manera" (Muñoz Castillo, 2020) ${ }^{1}$.España es un país uranífero, que por cuenta de las muy dispares políticas energéticas practicadas en las últimas cuatro décadas, no ha sabido aprovechar las potencialidades de este recurso energético. Pese a la limitada existencia de centrales nucleares en el territorio español -7 reactores activos entre Tarragona, Cáceres y Guadalajara-, en el sur de España se ha generado un notable patrimonio nuclear en forma de minas, fábricas de uranio, proyectos de centrales nucleares, así como zonas afectadas por radiactividad debida a distintos accidentes y causas. En este sentido, el sur de España es singular, porque las centrales nucleares, propiamente dichas, no constituyen lo esencial de su patrimonio nuclear, como si lo es, en la mitad septentrional de la península Ibérica.

El conjunto de organismos públicos gestores de todo aquello relacionado con la energía nuclear (JIA-EPALE, Junta de Investigaciones Atómicas-Sociedad Anónima de Estudios y Patentes de Aleaciones Especiales /JEN, Junta de Energía Nuclear/CSN, Consejo de Seguridad Nuclear /CIEMAT, Centro de Investigaciones Energéticas, Medioambientales y Tecnológicas /ENRESA, Empresa Nacional de Residuos Radiactivos, S.A.) ha tenido una intervención directa en la gestión de este conjunto de recursos. Sin embargo, es necesario realizar un análisis crítico de la situación actual del patrimonio nuclear. Para ello, la ciencia geográfica y especialmente, la geografía regional, aporta método y herramientas de análisis muy indicadas para llevar a cabo esta labor a fin de obtener una visión de conjunto (física, paisajística-ambiental, población, economía) sobre una realidad que, en el fondo, es bastante desconocida y que se ha prestado a visiones predeterminadas por juicios a favor o en contra, donde no cabía término medio. La realidad territorial actual de las áreas que cuentan con infraestructuras nucleares en el sur de España es la de un conjunto de lugares afectados por esta serie de actividades que, por lo común, han quedado marcados de forma negativa.

Debe recordarse que, en la actualidad, España cuenta con una potencia instalada en energía nuclear que supera los $7.000 \mathrm{MW}$, que generan el $21 \%$ de la producción de energía eléctrica. Por encima del debate sobre la necesidad actual de la energía nuclear, que ha tornado en una cuestión de calado ideológico, es necesario elaborar un análisis geográfico que permita sacar conclusiones que señalen las potencialidades de unos lugares unidos por el aprovechamiento tradicional de un recurso mineral, el uranio, bien por su producción o por la gestión de sus residuos. El análisis geográfico regional se muestra como la disciplina útil para la configuración y constitución de un corpus que permita elaborar aproximaciones posteriores de carácter más específico.

No son nada numerosos los trabajos sobre patrimonio nuclear, desde los supuestos que aborda esta investigación. Generalmente se han analizado las propias centrales nucleares como elemento central del patrimonio nuclear de un territorio. Es el caso de Francia, donde las centrales nucleares, como principales elementos del patrimonio nuclear, han sido objeto de aproximaciones en ocasiones no específicamente académicas, como las de Mathieu (2020), Bezat (2021) y Wakim (2021), sin olvidar el amplio material de la web pnc-france.org, o los trabajos recientemente publicados en el portal de especialización ambiental "Reporterre". En Alemania, destaca el trabajo de Mihm (2019) sobre el "indeseable patrimonio" nuclear.

En España, el patrimonio minero ha merecido diversos trabajos donde se señala su valor como patrimonio y recurso potencialmente utilizable en la promoción turística de una localidad o ámbito comarcal. Son destacados los trabajos de Cañizares $(2011,2013)$, sobre las minas de Almadén o los parques mineros como recurso turístico, el de Pérez Macías et al. (2016) sobre las minas de Río Tinto (Huelva), Romero Silva (2019)

1 Vid. Muñoz Castillo, J.A. (2020). Patrimonio Nuclear del Sur de España. Un estudio geográfico (Tesis doctoral inédita). En este trabajo no se incluyen las centrales nucleares dentro del patrimonio nuclear que, por lo demás, son elementos principales de la actividad de producción energética en España y si forman parte del mismo, como elementos básicos del mismo, en la mitad norte de nuestro país. 
sobre el inicio de la siderurgia en Málaga o las investigaciones de Espejo Marín (2002) relativas a la producción de electricidad de origen nuclear, que desarrolló a primeros de siglo; sin olvidar el trabajo de Gonzalvo Salas et al. (2018) sobre Vandellós.

El uranio ha sido empleado desde la antigüedad para diferentes usos, aunque no fue aislado hasta 1789 por Martin H. Klaproth. Se ha empleado, tradicionalmente, en la artesanía del vidrio y la cerámica. Durante los siglos XIX y XX se fueron descubriendo los distintos minerales uraníferos, así como sus principales yacimientos para extracción. Del mismo modo, se le fueron dando distintas utilidades asociadas a su potencial energético y a la radiactividad. En España fue el ingeniero cordobés Antonio CarboneII-Trillo Figueroa ${ }^{2}$ (1885-1947) el primero en hallar minerales uraníferos en 1917-18. Se reconocen hasta 76 mineralizaciones uraníferas en España, 32 en rocas plutónicas (y en general, las más susceptibles de tener rentabilidad económica), 20 en rocas metamórficas y otras 22 en rocas sedimentarias. En la zona objeto del presente estudio, 6, 9 y 2 respectivamente. Bastante desiguales y con una rentabilidad mínima en general a excepción de los yacimientos de El Cabril, Cardeña y la Sierra de Andújar. A estos antiguos yacimientos ya clausurados, se pueden sumar la antigua Fábrica de Uranio de Andújar "General Hernández Vidal", la Fábrica "experimental" de ENUSA en La Haba (Badajoz) y la Central Nuclear nunca desarrollada de Valdecaballeros. También el entorno de la diputación (pedanía) de Palomares, sita en el municipio almeriense de Cuevas de Almanzora, escenario del importante accidente aéreo-nuclear ocurrido en 1966 (figura 1).

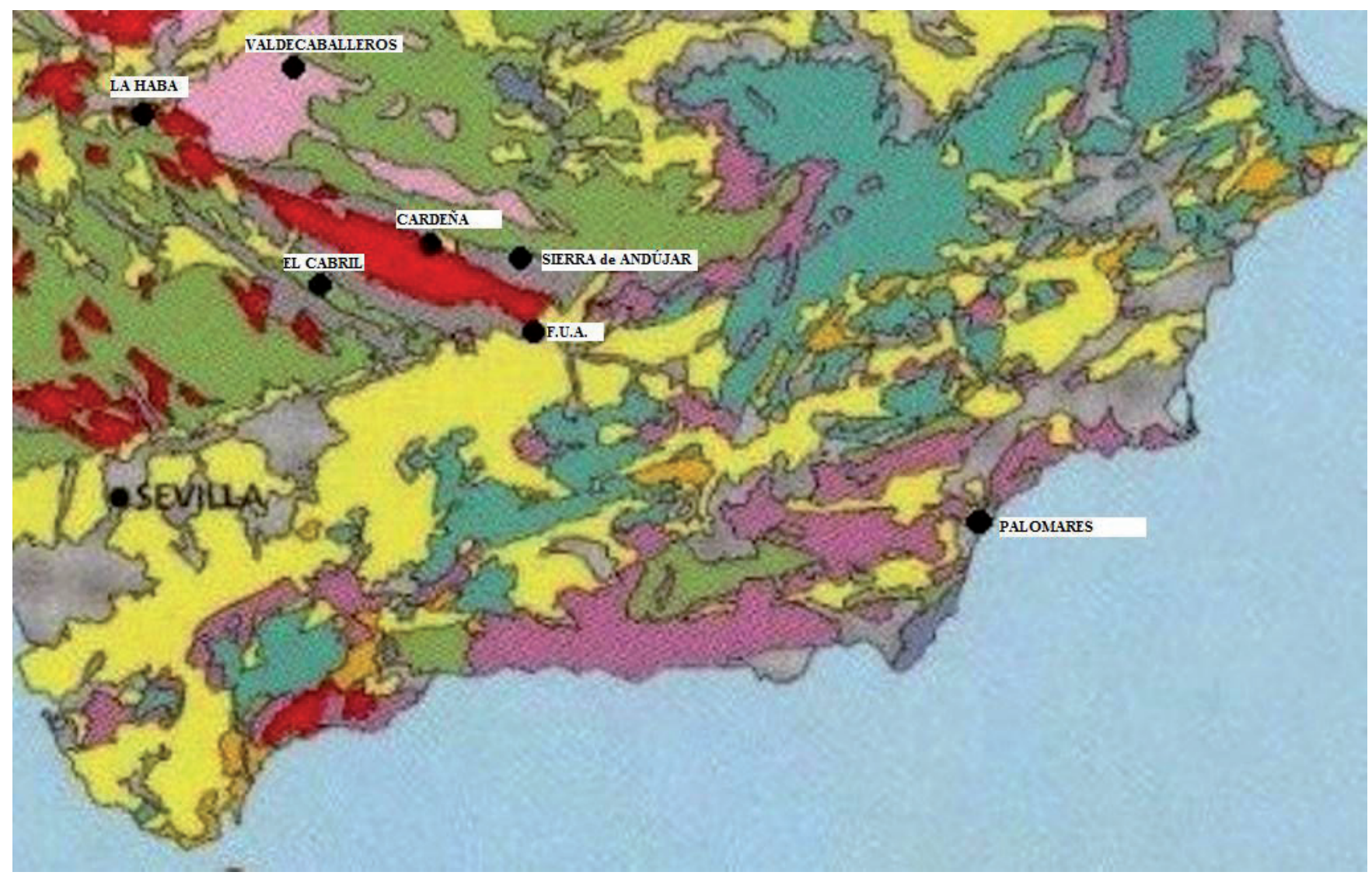

Figura 1. Cartograma geológico con localización de los lugares patrimonio nuclear objeto de estudio. Fuente: Elaboración propia sobre base cartográfica del IGME (Mapa Geológico de España). 
El proceso de fabricación del combustible nuclear de uranio -el precipitado de diuranato de amonio o "yellow cake"- implica una serie de procedimientos fisicoquímicos con hasta trece fases distintas desde la extracción en la mina hasta la neutralización de estériles, envasado y distribución del producto final a las centrales nucleares. La energía nuclear es, en la actualidad, una pieza importante en el mix de producción energética de España (20-25\%) (Espejo, 2001, 2002). Y a pesar de las controversias que conlleva su desarrollo y uso, el reemplazo a corto plazo que supone el cierre previsto de las centrales nucleares en España, resulta complejo en el contexto de precios altos de la energía que se registra a comienzos de la tercera década del presente siglo, debido al aumento de precios del gas natural, procedente para el caso español de Argelia y Rusia (gasoducto europeo). Espejo Marín y Capel Molina (2007) analizaron la implantación de las nuevas centrales de ciclo combinado (gas natural) en España, más eficientes desde el punto de vista energético y menos contaminantes. Entre los años 2002 y 2006, se construyeron 21 centrales de ciclo combinado, con una potencia de $15.175 \mathrm{MW}$, el doble de la capacidad nuclear existente en España y por tanto suficiente para la sustitución de las centrales térmicas tradicionales y las nucleares que se fueran cerrando. Otra cuestión, como se ha señalado, es el coste de producción energética, debido al alto precio del gas natural y a la obligación de reducción de emisiones impuesta por Europa para 2030 y 2050, en su marco de actuación para el cumplimiento del Acuerdo de París (2014). De manera que, la cuestión nuclear se convierte en un tema de debate y actuación importante para los próximos años, dentro de la estrategia energética a medio plazo (horizonte 2050) de España, por definir.

Recordemos que la energía nuclear de uso para satisfacción de demandas energéticas en España tiene sus antecedentes en el Decreto de 4 de octubre de $1945^{3}$ que nacionalizó la minería del uranio, que al cabo de diez años se desarrolló, fundamentalmente en yacimientos de Soria, Salamanca, Cáceres, Badajoz, Córdoba y Jaén, con dos ramas: la militar, con el denominado "Proyecto Islero" (1964-1984) (Valverde y Carpintero, 2016) y la civil, que tuvo tres etapas principales. A saber: la de los reactores "experimentales" CORAL, ARGOS y ARBI, la de las centrales de "primera generación" (Garoña, Zorita, Vandellós I) y las de las centrales en uso o de "segunda generación" (Almaraz, Trillo, Vandellós II y Cofrentes). Como señala Espejo (2002), "en 1984, de acuerdo con el contenido del Plan Energético Nacional aprobado dicho año, fueron paralizadas las obras de las cinco centrales nucleares que se hallaban en fase de construcción: Lemóniz I y II en Vizcaya con una potencia de $930 \mathrm{MW}$ cada una, Valdecaballeros I y II en Badajoz con 975 MW de potencia unitaria, y Trillo II en Guadalajara con 1.041 MW". Esta decisión adquirió resolución definitiva con la aprobación de la moratoria nuclear de 1986 que, de no haberse aplicado, podría haber llevado a España, país uranífero y con potencial nuclear ${ }^{4}$ a poseer en su territorio la respetable cifra de treinta reactores nucleares (Fernández-Arias et al., 2021), además de haber asegurado, a corto plazo (horizonte 2030) la demanda de energía eléctrica en el contexto de cambio energético impuesto por la Unión Europea para el cumplimiento de los objetivos de reducción de emisiones de gases de efecto invernadero (principalmente CO2) incluidos en el Acuerdo de París de 2014. Mientras, la minería fue decayendo a partir de 1970, hasta quedar reducida a pocos yacimientos, en concreto el polémico caso, a cielo abierto, de Retortillo (Salamanca), paralizado por las deficiencias en la documentación presentada ante la Junta de Castilla y León el día 12 de abril de 20215, y otros proyectos aún por concluir.

El presente estudio tiene como objetivos principales: a) delimitar las infraestructuras que integran el patrimonio nuclear en el sur de España; b) realizar un diagnóstico del estado de las mismas, sin olvidar el recorrido histórico que explica su evolución y situación actual; c) elaborar unas propuestas de actuación para poner en valor este patrimonio nuclear, que minimice la percepción, generalmente negativa, que acompaña a estos espacios en relación con la peligrosidad asociada al uranio.

3 BOE, 19 de octubre de 1945.

4 Esta afirmación está basada en el estudio del Plan Nuclear de la JEN de 1971.

5 Vid. documentación en la página del Congreso de los Diputados (www.congreso.es). 


\section{FUENTES Y MÉTODO}

Las fuentes empleadas para la realización del presente trabajo han sido, básicamente, dos: a) documentales, con revisión de ensayos e informes en cada uno de los elementos que componen el patrimonio nuclear del sur peninsular; b) de campo con visita a los lugares estudiados en este trabajo, que ha servido para tener un contacto directo con el medio natural y la sociedad de cada uno de los emplazamientos analizados, donde se han realizado entrevistas personales con la población local.

Por tanto, la hipótesis de partida del presente trabajo se puede formular del modo siguiente: "en distintos lugares de Andalucía y la provincia de Badajoz se encuentran una serie de lugares e infraestructuras relacionados con la minería del uranio, la industria de transformación de éste, la producción de energía nuclear y las consecuencias de accidentes relacionados con éstos, que, aparte los estigmas con respecto a su entorno, merecen un análisis geográfico.

El método de trabajo ha sido inductivo: a partir del análisis particular y detallado de los elementos que componen el patrimonio nuclear del sur de España, se ha realizado un diagnóstico detallado de su estado actual. Todo ello orientado a la elaboración de propuestas que permitan revalorizar estos espacios en la actualidad. Una pieza fundamental en este análisis ha sido, como se ha señalado, el trabajo de campo y las entrevistas personales con las poblaciones locales realizadas en los distintos territorios componentes del objeto de estudio (Andújar, Cardeña, El Cabril, Palomares, La Haba y Valdecaballeros).

Se realizaron un total de cincuenta entrevistas en los emplazamientos de patrimonio nuclear señalados, siguiendo el siguiente patrón de consulta6:

1. Relación con el elemento estudiado.

2. Conocimiento de los efectos de la radiactividad.

3. Conocimiento de potenciales víctimas de la radiactividad.

4. Relación laboral con las infraestructuras (si la hubiera).

5. Relación con los responsables de las mismas (si la hubiera).

6. Visión propia de lo realizado hasta el momento con el elemento estudiado.

7. Propuestas sobre lo que se debería hacer (si proceden).

8. Razonamientos sobre lo que no se debería haber hecho (si así procede).

9. Cualquier otra cuestión (o cuestiones específicas) del elemento estudiado.

En los casos de Andújar, Cardeña y El Cabril, hubo un notable paralelismo entre trabajos de campo y de documentación que derivaron en los resultados plasmados en el presente artículo. Sin embargo, en el estudio de los elementos de patrimonio nuclear de la provincia de Badajoz se realizaron primero las visitas de campo y se confirmaron las hipótesis de trabajo derivadas de estos encuentros con la documentación consultada con posterioridad.

Debe señalarse que las jornadas de campo se realizaron, básicamente, en meses de pandemia (mayo-septiembre de 2020) con lo que hubo que adaptar la programación de las visitas a las restricciones de movilidad y aforos en los destinos visitados. E, igualmente, ha ocurrido con las visitas a archivos provinciales y locales para la consulta de documentación sobre los distintos lugares que integran el patrimonio nuclear del sur de España, que hubo de adaptarse a las difíciles condiciones de la situación sanitaria vivida en nuestro país a lo largo del año 2020. Se han consultado los siguientes archivos:

- Archivo personal de D. José Soto Cepas, con documentación proporcionada en Andújar, de modo presencial.

- Biblioteca Histórica del Instituto de Educación Secundaria "Séneca".

6 La realización de los cuestionarios no tuvo la misma respuesta en todos los lugares objeto de estudio. La escasa población y muy envejecida existente en algunas localidades y la negativa a hablar de esta cuestión, en numerosas ocasiones, dificultó el trabajo de campo realizado para desarrollar este estudio. 
El resto de documentación de archivo se ha consultado en modo on-line:

- Archivos de la revista Estratos, disponibles en la web de ENRESA.

- Archivos del CIEMAT, disponibles en la web homónima.

- Base de datos Dialnet de la Universidad de La Rioja.

- $\quad$ Base de datos Latindex.

- Base de datos Academia.edu.

Una parte de publicaciones empleadas en la redacción de este trabajo fueron descargadas on-line. Aquellas que no lo fueron, se encuentran en las bibliotecas personales de los autores.

\section{RESULTADOS: DIAGNÓSTICO DEL PATRIMONIO NUCLEAR EN EL SUR DE ESPAÑA.}

Se presenta, a continuación, el diagnóstico del patrimonio nuclear del sur de España. Se han analizado 6 elementos tales como minas, fábricas, almacenes y áreas afectadas por radiactividad sobrevenida:

- Las minas de la Virgen de la Cabeza y la FUA en Andújar.

- Las minas de Cardeña-El Cerezo.

- El depósito de almacenamiento nuclear de El Cabril

- Palomares.

- Valdecaballeros.

- La Haba.

En su conjunto, son localidades de las Comunidades Autónomas de Andalucía y Extremadura que, salvo en la localidad de Palomares, sufren en los últimos años los efectos de la despoblación del interior peninsular y de la pérdida de actividad económica relacionada con la actividad nuclear (López, 1998). Aunque en su mayoría presentan una riqueza natural y de paisaje que otorga un potencial de desarrollo para actividades de ocio (tabla 1).

Tabla 1. Datos básicos de las localidades con Patrimonio Nuclear del sur de España.

\begin{tabular}{|c|c|c|c|}
\hline Localidad & Población (2020) & $\begin{array}{c}\text { Actividad económica } \\
\text { principal }\end{array}$ & Valores del territorio \\
\hline Andújar (Andalucía) & 36.615 & Servicios, construcción & $\begin{array}{l}\text { Paisaje de olivar. Patrimonio } \\
\text { monumental. Parque } \\
\text { Natural Sierra de Andújar }\end{array}$ \\
\hline Cardeña (Andalucía) & 1.471 & Agricultura, servicios & $\begin{array}{l}\text { Riqueza paisajística } \\
\text { (dehesas). Parque Natural } \\
\text { Sierra de Cardeña y Montoro }\end{array}$ \\
\hline $\begin{array}{l}\text { El Cabril. Hornachuelos } \\
\text { (Andalucía) }\end{array}$ & 4.480 & $\begin{array}{l}\text { Agricultura. } \\
\text { Depósito nuclear }\end{array}$ & $\begin{array}{l}\text { Paisaje natural. Parque } \\
\text { Natural de la Sierra de } \\
\text { Hornachuelos. } \\
\text { Actividad cinegética }\end{array}$ \\
\hline $\begin{array}{l}\text { Palomares. Cuevas de } \\
\text { Almanzora (Andalucía) }\end{array}$ & $\begin{array}{c}14.455 \\
\text { (1.996 en el núcleo de } \\
\text { Palomares) }\end{array}$ & $\begin{array}{l}\text { Servicios. Construcción. } \\
\text { Turismo. Agricultura de } \\
\text { vanguardia }\end{array}$ & $\begin{array}{l}\text { Playas. Patrimonio } \\
\text { monumental }\end{array}$ \\
\hline $\begin{array}{l}\text { Valdecaballeros } \\
\text { (Extremadura) }\end{array}$ & 1.065 & Servicios. Turismo & $\begin{array}{l}\text { Embalse de García Sola. } \\
\text { Reserva de la Biosfera de la } \\
\text { Siberia }\end{array}$ \\
\hline La Haba (Extremadura) & 1.219 & Servicios. Turismo & Patrimonio monumental \\
\hline
\end{tabular}

Fuente: INE eInstituto de Estadística y Cartografía de Andalucía. Elaboración propia. 
En todos los casos, la actividad nuclear ha marcado la evolución socioeconómica contemporánea de estas localidades. En la mayoría de ellos, generando puestos de trabajo directos e ingresos que se perderán una vez cesada la actividad, sometiendo a estas localidades a años de depresión económica que apenas se ha podido recuperar por el desarrollo de la actividad de servicios y turismo de interior. Asimismo, tras el cese de esa actividad, la población se ha desplazado a las cabeceras comarcales o provinciales. Incluso, los efectos de la radiactividad sobre la salud de los habitantes han tenido efectos funestos para la perdida de vitalidad demográfica. En el caso de Palomares, tras años de estigma debido al accidente nuclear sobrevenido, la actividad de la construcción, el turismo y la agricultura de vanguardia desarrollada en las tres últimas décadas ha impuesto una dinámica económica importante.

\subsection{Andújar: las minas de la Virgen de la Cabeza y la FUA}

Se trata de un patrimonio doble: por un lado, las minas situadas al noroeste del Santuario de Ntra. Sra. de la Cabeza (Navalasno, Montealegre, Raso de los Machos y la Virgen), activas entre 1955 y 1970, pero selladas y restauradas en 1996; y por otro, la Fábrica de Uranio de Andújar (FUA) “General Hernández Vidal”, a las afueras de Andújar y activa entre 1959 y 1981, desmantelada, sellada y restaurada entre 1991-94. Si es destacable la labor de ENRESA en las labores de sellado de las minas antedichas-situadas dentro del Parque Natural de las Sierras de Andújar-, la tragedia humana generada por la FUA, situada al lado del río Guadalquivir y de la propia ciudad isturgitana, trasciende los considerables problemas medioambientales generados por la carencia de medidas de protección radiológica, tanto para los trabajadores como para el entorno (Muñoz Castillo, 2021).

Las minas uraníferas de la Sierra de Andújar-Virgen de la Cabeza se encuentran sobre un relieve herciniano, con escasa población y actividades económicas (forestal, cinegética y ganadera). De ellas se extrajo pecblenda y torbernita. Por el contrario, la antigua FUA se encuentra sobre un relieve plio-pleistoceno, aluvial, con gran potencialidad agronómica e inmediato a Andújar, que es una localidad que presenta todos los estándares de una "agrociudad" (figura 2). Si la antigua zona minera presenta escasísima población, la población de Andújar, junto con sus otros poblados de colonización y pedanías, presenta en la actualidad una escasa dinámica demográfica. Es un trasunto de la evolución de la población de la España interior.

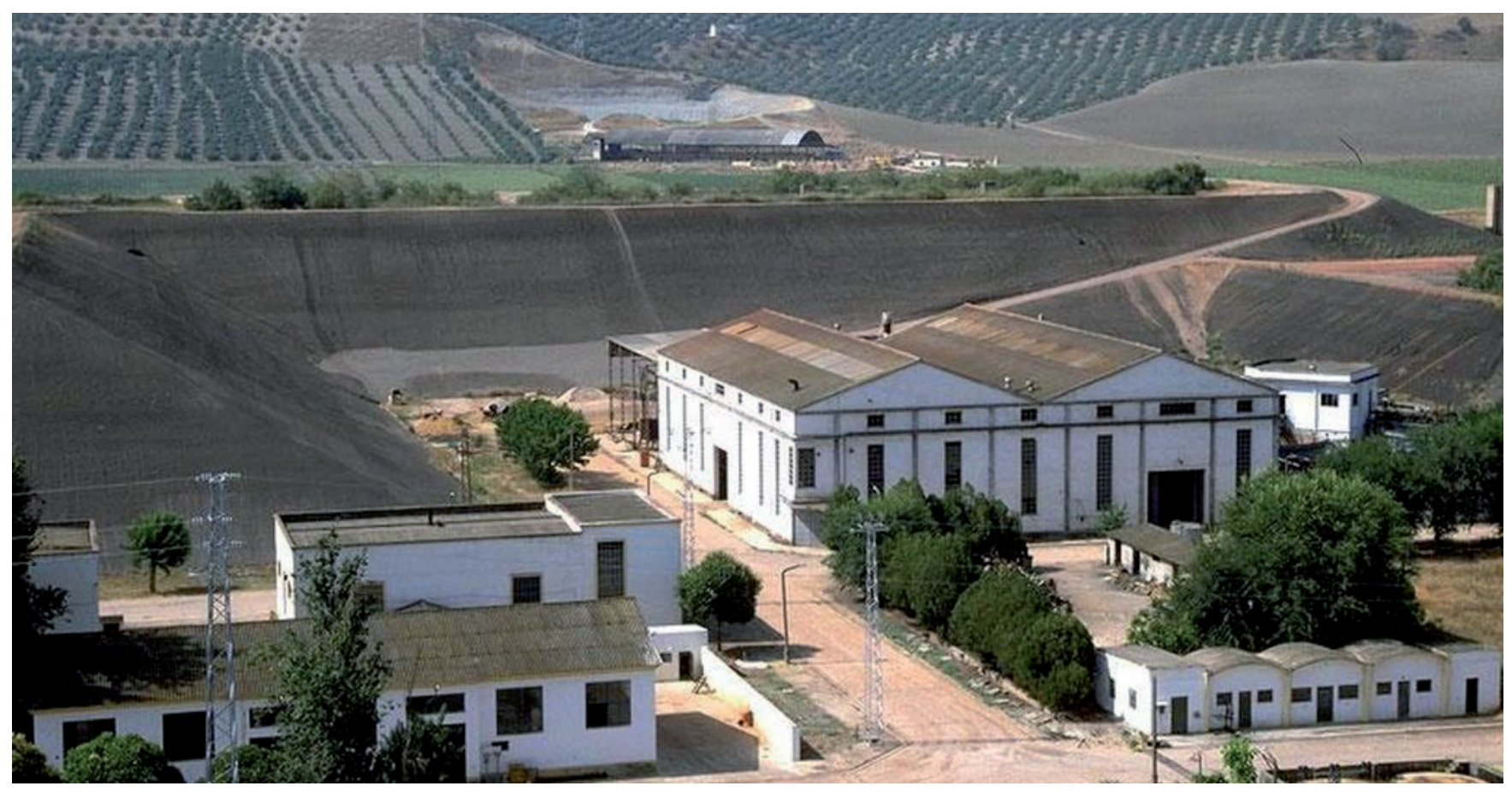

Figura 2. Imagen de la Fábrica de Uranio de Andújar -FUA-, en la actualidad. Fuente: www.vivajaen.es 
Andújar y su término municipal son "una comarca en sí misma". De transición entre la Sierra, su piedemonte, el Valle del Guadalquivir y la Campiña. Con una gran variedad de usos del suelo y dinámicas de aprovechamiento económico. En consecuencia, la dedicación de la primera a la ganadería, explotaciones forestales y cinegéticas, el uso variado de la segunda, destacando el uso como "segundas residencias", la oleicultura en piedemonte y campiña, la agricultura del valle y la dedicación mixta del entorno de Andújar.

La minería tuvo una tradición previa en Andújar, concluida con el cierre de las minas de uranio en 1970. No hubo proyectos de instalar la FUA a bocamina. Sin embargo, ésta se ubicó en un lugar con una proyección logística excelente, pero con una palmaria inaptitud en lo radiológico, a orillas del río Guadalquivir sobre suelos aluviales. La FUA "General Hernández Vidal" se proyectó y creó entre 1955-58, operando desde 1959 a julio de 1981(Muñoz Castillo, 2017). Tuvo 126 trabajadores y 8 técnicos. Siempre la dirigió el Dr. Manuel Perarnau. Se convirtieron en yellow cake ${ }^{7}$ minerales procedentes de la Sierra de Andújar, Cardeña, El Cabril y desde 1965 a 1975, La Haba. También se obtuvo algo de cobre de la torbernita. El propio libro del Dr. Perarnau alude a las altísimas dosis de radiactividad en ciertas fases del proceso ${ }^{8}$. No era la única carencia. Había más:

1. Carencia de comedor laboral, instalado después en el que hasta entonces había sido almacén de los bidones de "yellow cake", sin descontaminación previa alguna.

2. Ausencia de lavandería, instalada mucho tiempo después, por lo que gran cantidad de polvo radiactivo pasó a la red de aguas potables de Andújar al lavarse las ropas laborales en las casas de los trabajadores.

3. Falta de equipos de protección adecuados para los trabajadores. Los testimonios sobre esta realidad son abundantes, así como el hechode que "sólo se sacaban cuando había alguna visita importante" .

4. El propio trato del Dr. Perarnau y sus subordinados técnicos sobre el personal, calificado como "despótico" por los escasos supervivientes.

El primer fallecido por males relacionados con la exposición a la radiactividad se registró en 1970. Desde entonces, el goteo fue continuado hasta hoy, en su mayor parte por enfermedades oncológicas. Cuando se cerró la FUA en 1981, 30 trabajadores fueron enviados a la planta de ENUSA en La Haba. A excepción de algunos empleados que fueron dedicados a tareas de mantenimiento y un reducido número de técnicos que fueron enviados a Madrid, la mayor parte de los trabajadores fueron despedidos (Utrera Cardeñas, 2009).

Entre 1988 y 1991, la FUA estuvo en situación de casi abandono. Y, si bien sus labores de restauración y sellado se llevaron a cabo entre 1991 y 1994, las de las antiguas minas se llevaron a cabo en 1996, espoleadas por estar dentro de un Parque Natural. La antigua FUA, conocida como "La Escombrera", sigue en fase de vigilancia radiológica, prorrogada después de $2017^{10}$. Hasta hoy, son escasísimas las publicaciones técnicas de ENRESA que abordan la historia y evolución de la FUA y las actividades llevadas a cabo. Es un tema incómodo que no interesa publicitar. De las minas ya no queda nadie. Se intenta disimular o maquillar de una manera u otra, pero queda como ejemplo de lo que no se debe hacer a la hora de poner en marcha una fábrica de concentrados de uranio, ni en el momento de su desmantelamiento y sellado; y lo mismo cabe señalar del propio cierre de las antiguas minas.

\subsection{Las minas de Cardeña-El Cerezo}

El caso cardeñero está muy conectado al anterior. Sus minas pertenecen, como las de la Sierra de Andújar, a la cadena de batolitos y culms de Sierra Morena, de milenario aprovechamiento minero. Los pozos

7 Nombre común utilizado para el precipitado de diuranato de amonio, empleado como combustible en las centrales nucleares de fisión.

8 Vid. Perarnau (1966), pág. 9.

9 Afirmaciones obtenidas en el trabajo de campo realizado para la elaboración de este artículo.

10 Estaba previsto su cambio en esta fecha, pero las mediciones de ENRESA y el CSN aconsejaron ampliarla. 
uraníferos, situados en torno a la antigua aldea del Cerezo, fueron los de El Cano, San Valentín y Ovejo, batolíticos (figura 3). Más distanciado, el de Trapero, sobre el culm. De ellos se extrajeron pecblenda, coffinita y torbernita, tratados en la FUA de Andújar. Su actividad se desarrolló entre 1953 y 1968 y en 1970. Después concluyó. Hasta 1998 no se emprendieron las labores de restauración y sellado de las minas, quizá las que más quedaron influidas por los proyectos estadounidenses UMTRA ${ }^{11}$.

Son suelos muy pobres, análogos a los de la sierra de Andújar, adehesados a finales de la Edad Moderna y de escaso aprovechamiento más allá del ganadero extensivo. La actividad minera influyó directamente en la dinámica demográfica y migratoria de Cardeña y de modo particular desde 1970 hasta hoy. Ni siquiera el acicate de la creación del Parque Natural de las Sierras de Cardeña y Montoro en 1989, así como los proyectos asociados al desarrollo sostenible de la zona, han podido revertir esta tendencia. La escasa actividad actual de Cardeña se sustenta en una economía mixta, de base más ganadera que agrícola, y con escasísimos servicios.

Las minas cardeñesas de uranio fueron estudiadas desde principios del siglo XX por el ingeniero Antonio Carbonell Trillo-Figueroa. El primer uranio que se transformó en la Facultad de Ciencias de Madrid, en 1952, procedía de pozos de Cardeña. Los mineros del uranio cardeñés fueron bien tratados por sus jerarcas de la Junta de Energía Nuclear (JEN), pues se les reconocieron sus enfermedades laborales-silicosis y exposición a la radiactividad-, aparte ser trasladados a otras explotaciones uraníferas como Saelices el Chico, Albalá y La Haba. Sin embargo, el desmantelamiento, sellado y restauración de las antiguas minas fueron muy tardíos: en 1998-99, de modo análogo al caso de la sierra de Andújar, y animados por la consideración de Parque Natural de los terrenos de las antiguas minas.

Los estudios sobre las minas de Cardeña son sumamente escasos; incluso los de carácter técnico, editadas por ENRESA. Sería conveniente dar una mejor difusión a este elemento del patrimonio que ha quedado, en general, bien restaurado y reintegrado en el paisaje y protegido bajo la figura de Parque Natural.

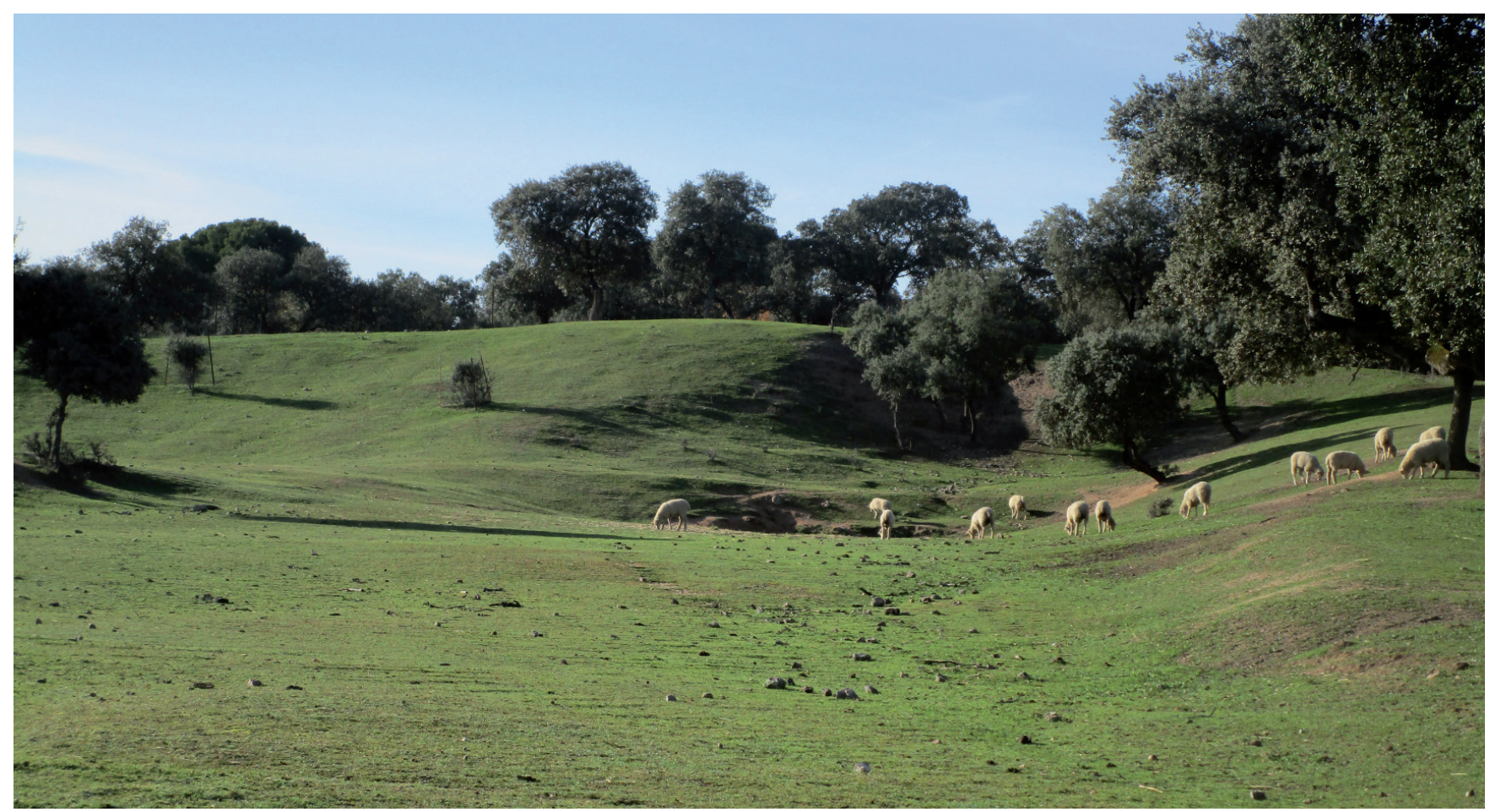

Figura 3. Aspecto actual de la antigua bocamina de El Cano (Cardeña), restaurada y vuelta a sus usos pastoriles tradicionales. Fuente: Autor (Muñoz, diciembre 2020).

11 Siglas de Uranium Mines Tailing Remedial Action (Acción de Reforma de Explotaciones Mineras de Uranio), conjunto de proyectos aprobados desde los años sesenta del siglo pasado por el DOE de los Estados Unidos. 


\subsection{El Cabril: principal activo del Patrimonio Nuclear del Sur de España}

El Cabril, se sitúa al noroeste de la provincia de Córdoba. Ese es el nombre del Almacén Centralizado de Residuos Radiactivos de ENRESA, enclavado en la finca homónima, en la ladera oriental de la Sierra Albarrana. Es el principal activo del Patrimonio Nuclear del Sur de España, habida cuenta que ha mantenido un siglo de actividades relacionadas con la minería del uranio y la gestión de los residuos nucleares generados por las distintas actividades en las que se emplean metales radiactivos (Muñoz, 2010).

En origen fueron distintas minas y cortas de uranio, berilo y micas, desde su descubrimiento en 1918 por el ingeniero, empresario e intelectual cordobés Antonio Carbonell Trillo-Figueroa hasta el cierre por la Junta de Energía Nuclear (JEN) de la Mina Beta en 1961 (Muñoz, 2012). Con posterioridad, a partir de esa misma fecha, se acondicionó para almacenamiento de residuos radiactivos en distintos emplazamientos de la finca, con una especialización e incremento de las medidas de seguridad y protección radiológica, cada vez mayores y mejores, por su propio carácter, no sólo industrial, sino de I+D+i propio y todo ello reforzado si cabe aún más, por ser el único almacenamiento de residuos radiactivos que hay en España, mientras que no se lleve a cabo la infraestructura para el almacenamiento y gestión de los residuos de alta actividad, tanto en modo temporal de combustible (ATC) como con carácter permanente(AGP), que son de extrema necesidad (Enresa, 1986-2019).

El Cabril se asienta sobre un zócalo precámbrico y caledoniano dispuesto en bandas de dirección NO-SE, bordeado por formaciones hercínicas, bastante abarrancadas. La pobreza de los suelos (inceptisoles) ha limitado mucho las actividades al pastoreo, la minería, la caza y la explotación forestal (figura 4). Además, su población ha sido por lo general escasa y dispersa. No en vano, con respecto a las localidades que lo rodean, hay un desierto demográfico cuyo centro es El Cabril. No hay población estable en un radio de acción superior a los 15 kilómetros. Y las localidades del entorno pierden población de modo continuado (Muñoz, 2020).

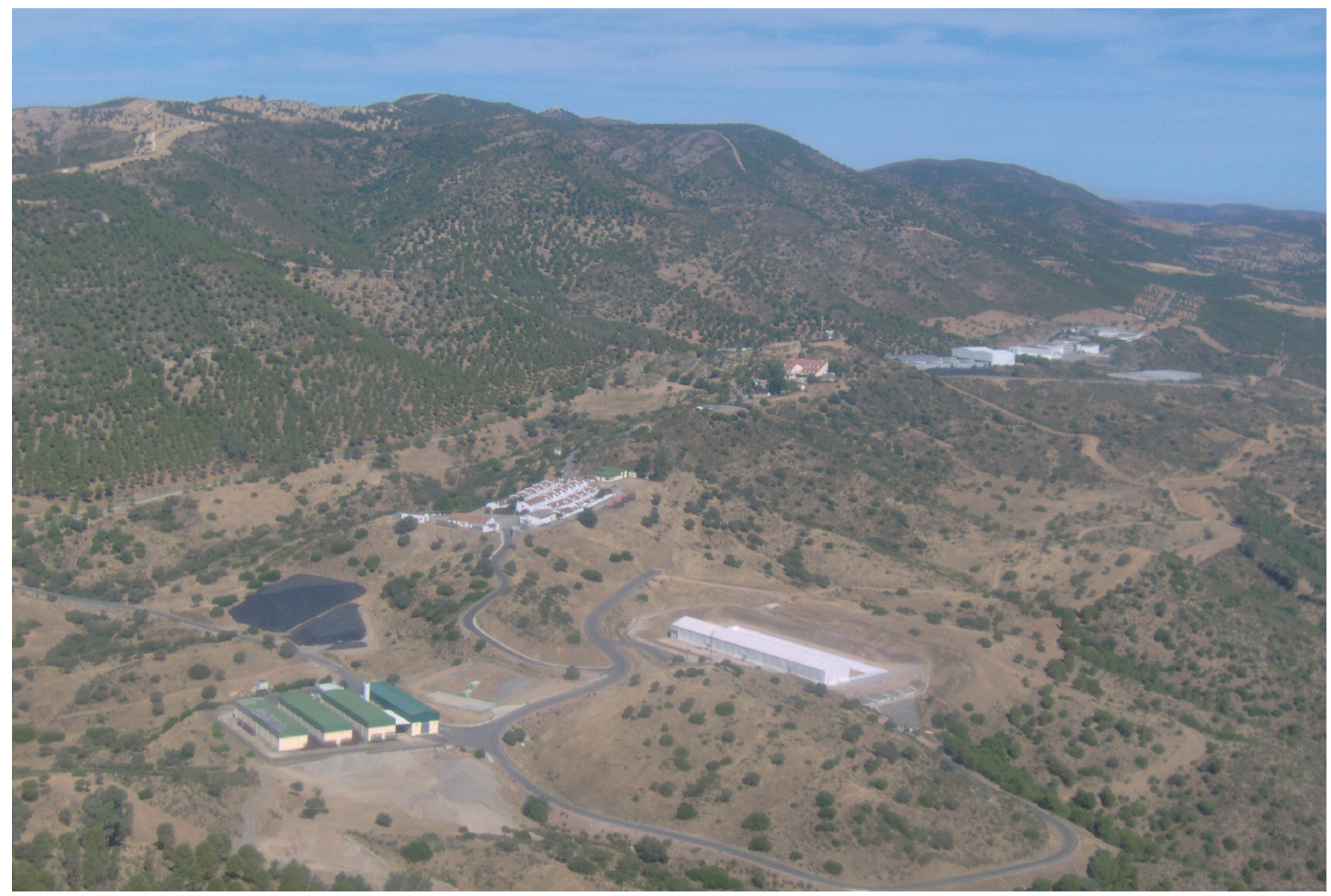

Figura 4. Vista de las instalaciones del Almacén Centralizado de Residuos Radiactivos de El Cabril (Córdoba). Fuente: Autor (Muñoz, junio 2020). 
El Almacenamiento Centralizado de Residuos de Muy Baja, Baja y Media Actividad de ENRESA en Sierra Albarrana-El Cabril es, sin duda alguna, la principal instalación industrial de alta tecnología del noroeste de la provincia de Córdoba. Su actividad se inicia con la extracción de berilos y micas de modo discontinuo desde 1918, y de modo continuado a partir de 1939 por iniciativa privada de BRESA, y, con posterioridad, por parte de EPALE-pública-, en las minas del Cabril y La Coma. Sin embargo, son las minas Beta (activa hasta 1961) y la cantera Diéresis (activa hasta 1975) las más productivas, tanto de micas como, en mucha menos medida, de uranio. Este uranio fue tratado en la FUA "General Hernández Vidal" hasta 1975. Gestionado por la JEN desde 1961 a 1984, el primer almacenamiento fueron las propias galerías de la mina Beta. Con posterioridad, se crearon los primeros almacenamientos temporales y permanentes -la antigua central térmica del Cabril-, y los módulos que hoy en día son temporales, al sur del emplazamiento actual. A partir de 1990 se crearon los módulos de almacenamiento principales, puestos en marcha en 1992. Hasta nuestros días se han creado otras tres celdas más para el almacenamiento de residuos nucleares de muy baja actividad, denominados "celdas 29, 30 y 31". Desde el año 2016, El Cabril limitó parcialmente la recogida de residuos hasta su ampliación aprobada ${ }^{12}$ en marzo de 2020, con otro módulo -“C"- y la llamada "celda 32".

La actividad de investigación y desarrollo, en los años de funcionamiento del almacén, ha sido constante y resulta francamente positiva, tanto por las aportaciones de tecnología para consumo propio, como por el ejemplo que suponen a nivel internacional. En su Complejo Tecnológico, las investigaciones, incluso las no estrictamente relacionadas de modo directo con la actividad nuclear, son continuas (Echag (ed.), 2000). Es un banco de pruebas, no sólo para mejorar las técnicas ya en uso, sino el futuro ATC, que se tendrá que desarrollar en las condiciones técnicas y de seguridad necesarias. Y esta consideración se puede aplicar al necesario AGP español que tendrá que desarrollarse en el futuro. Y, sin embargo, pese a las innegables actividades científicas, de gestión de residuos y de divulgación educativa (más de 7.000 visitas anuales), algo no acaba de producirse dentro de la política de comunicación de la empresa. Y ello porque sigue existiendo un desconocimiento importante de la instalación en el conjunto del país, así como un sesgo negativo sobre su funcionamiento. Presenta un potencial de recursos vinculados al ocio y las actividades deportivas, educativas y turístico-ambientales muy notable. Es, con mucho, la mejor instalación del Patrimonio Nuclear del Sur de España, por el volumen de actividad que desarrolla y su potencial como centro de innovación.

\subsection{Palomares: las secuelas del "broken arrow" ${ }^{13 "}$ español del 17 de enero de 1966}

La localidad de Palomares ${ }^{14}$ se sitúa al sureste del término municipal de Cuevas de Almanzora (NE de la provincia de Almería). No presenta en su subsuelo rocas ni minerales uraníferos. Tampoco ha tenido ninguna instalación nuclear de importancia significativa. Y, sin embargo, se ha incluido entre los lugares objeto de análisis en el presente trabajo por los hechos que exponemos a continuación:

En la mañana del 17 de enero de 1966 durante una rutinaria acción de repostaje en el aire de un bombardero "B52" y su avión-nodriza "KC 135" se produjo un choque entre éstos, que se incendiaron y estallaron en el aire. Aparte de las once muertes ocurridas en el acto de la tripulación de ambos aviones, cuatro bombas termonucleares " $\mathrm{H}$ " del modelo "B24", cayeron del avión "B52" con sus respectivas cargas de plutonio. Tres se pudieron recuperar rápidamente; la cuarta, al cabo de 80 días, gracias a la pericia de un pescador catalán ${ }^{15}$ avecindado en la cercana localidad murciana de Águilas (Álvarez de Toledo, 2002). Transcurrido más de medio siglo después sigue habiendo un número bastante considerable de parcelas que tras haber sido descontaminadas por la USAF en el propio año de 1966, y con posterioridad, por JEN/CIEMAT/ENRESA,

12 ENRESA pasó a depender del MITECO en 2019. Sin embargo, la suspensión del proyecto de ATC de Villar de Cañas supuso la contrapartida de la ampliación de El Cabril a partir de marzo de 2020.

13 Término utilizado en el lenguaje militar estadounidense para designar los accidentes en los que se produce pérdida de armamento nuclear por el motivo que sea.

14 Como pedanía que es, allí recibe el nombre de "diputación".

15 Francisco Simó Orts, desde entonces, Paco "el de la Bomba", tarraconense dedicado a la pesca del gambón rojo. 
siguen valladas y sometidas a vigilancia radiológica por presentar partículas de plutonio y altas dosis de radiactividad (figura 4).

El espacio geográfico de Palomares es una zona de contrastes entre paisajes naturales y entornos fuertemente antropizados. Sierra Almagrera, antigua zona minera, es un continuo espartizal, mientras las zonas bajas alternan zonas de invernaderos, arboricultura y núcleos urbanos o diseminados. Aparte, agroindustrias, zonas logísticas o la fábrica de Deretil en la cercana Villaricos. La población en estos municipios se ha triplicado en menos de tres décadas, debido a la demanda de la agricultura bajo plástico, y en menor medida, el turismo. Una tercera parte de la población actual (1883 hab. en 2020) son inmigrantes. Palomares y su entorno ya tenían una economía mixta antes del accidente, que ha ido modificándose. No obstante, a día de hoy, la principal actividad sigue siendo la agricultura intensiva de alto rendimiento, incluso en el entorno de las parcelas expropiadas por el CIEMAT y vigiladas por éste -y antes, por la JEN- desde 1966 al detectarse altos niveles de radiactividad.

Las parcelas en las que cayeron las tres bombas fueron valladas y descontaminadas por tropas de la USAF durante casi un año (figura 5). Se informó de modo tamizado sobre el accidente, ocultándose inicialmente su carácter nuclear. Mientras se expropiaban y vallaban parcelas contaminadas, se llevaron a cabo los acuerdos entre la JEN y el DOE estadounidense-los denominados acuerdos "Otero-Hall"-, para descontaminar la zona. Además, se llevó a cabo la operación propagandística del baño en la playa del entonces ministro de Información y Turismo, Manuel Fraga, y del embajador americano. El acuerdo JEN-DOE fue conocido como “Proyecto Indalo" y permitió la descontaminación de las parcelas afectadas y el traslado a almacenamientos nucleares de EE.UU. de los bidones con residuos. Primero a Savannah River y después, a Yucca Mountain. El Proyecto Indalo finalizó por parte estadounidense en 2009. Pero en 2015, conocida ya la extensión y entidad del "aerosol de plutonio" en la Sierra Almagrera, se firmó un nuevo acuerdo -el acuerdo "García Margallo-Kerry"que prevé la implementación de dinero para la descontaminación de las parcelas afectadas por el accidente de 1966, tanto en Palomares como en la Sierra Almagrera.

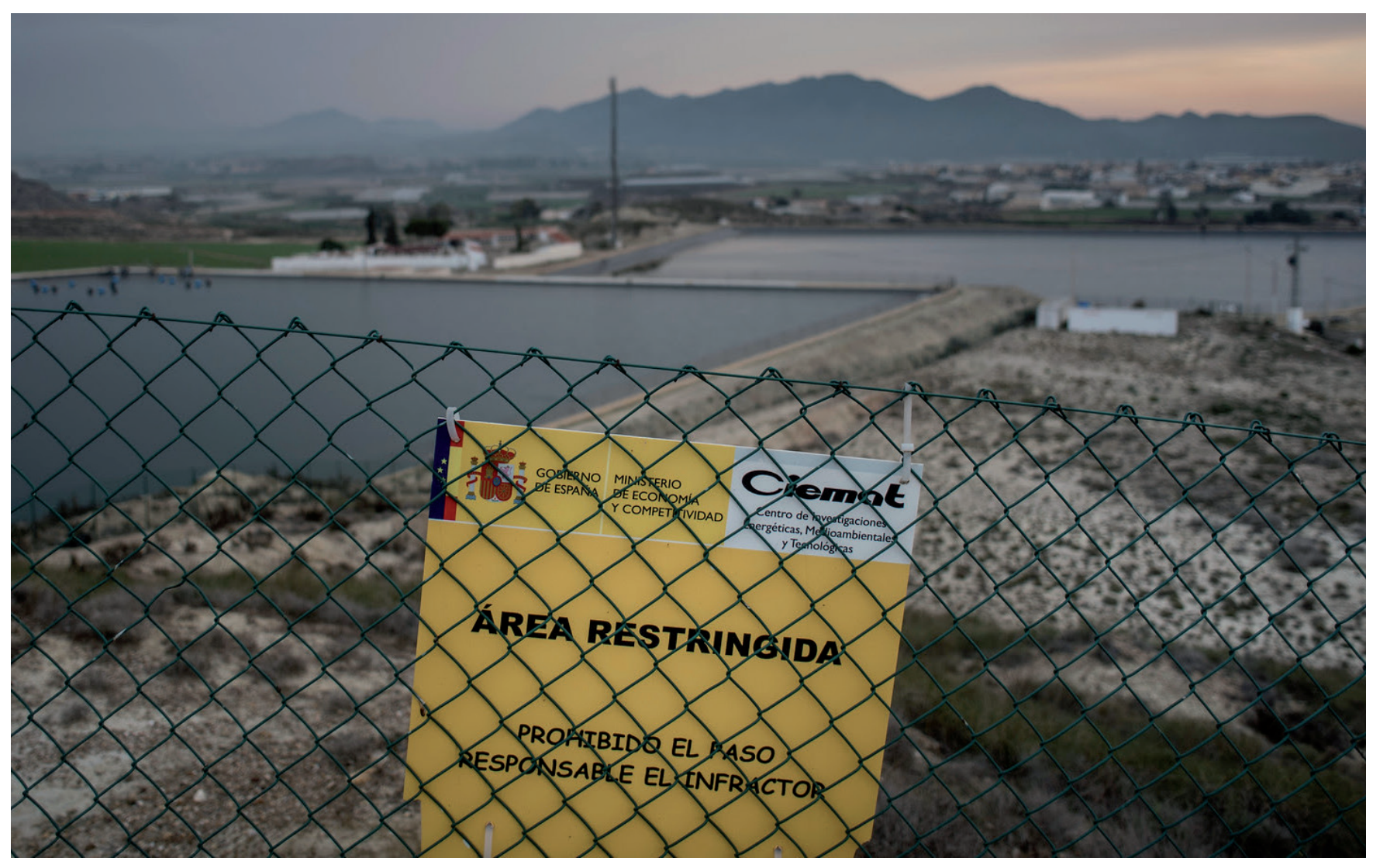

Figura 5. Balsas de Los Algarrobones, cerca de la localidad de Palomares. Fuente: Autor (Muñoz, 2018). 
Pese a expropiarse en principio 8 hectáreas, lo cierto es que hasta el día de hoy, alrededor de 150 personas han presentado trazas de plutonio en sangre (Muñoz, 2020). Y que, algunas han enfermado y muerto por causa de patologías compatibles con la exposición a la radiactividad. La desinformación fue muy considerable entonces (Herrera Plaza, 2019). Las mediciones de la JEN, tras la extracción, envasado y envío a los EE. UU. de los $25.000 \mathrm{~m}^{3}$ de residuos de tierra y elementos contaminados por parte de la USAF y la USN, han proseguido hasta hoy día. Y como consecuencia, se han perimetrado, vallado, expropiado y sometido a vigilancia otras parcelas. La evolución del tratamiento de las zonas contaminadas ha sido notable en el caso de Palomares. De hecho, la evolución tecnológica del propio conglomerado nuclear español permitió hallar en 2009 el "aerosol" o "pluma" de plutonio en Sierra Almagrera (Menéndez Suárez, 2016), y aunque tarde, permitió su perimetrado, vallado y expropiación. Pero a los residentes en la localidad de Palomares se les ha estigmatizado por los peligros de la radiactividad. "Oficialmente" no hay relación entre la exposición al plutonio y las enfermedades, pero en las "diputaciones" siempre se comenta. Junto con El Cabril, Palomares ha sido y es el otro gran banco de pruebas de los efectos de las radiaciones por distintas causas. Se han seguido llenando bidones con tierra contaminada, enviándose a los EE.UU., pero sería deseable mayor transparencia en la gestión de los residuos.

\subsection{Valdecaballeros: la central nuclear non nata de la Siberia Extremeña}

Valdecaballeros se encuentra al noroeste de la Siberia Extremeña, junto al río Guadiana embalsado por la presa de García de Sola. Es un pequeño pueblo agroganadero, sobre dos cuestas, entre dehesas y repoblaciones de pinos y eucaliptos, tranquilo, en el que, entre 1975 y 2001 se planteó un gran proyecto que, de no haber sido por la moratoria nuclear de 1986 y el Reglamento de Instalaciones Eléctricas de 1994, habría constituido un gran revulsivo para el desarrollo de esta zona, muy atrasada y bastante poco poblada: las Cuatro Villas ${ }^{16}$. Ese proyecto consistió en la construcción de una central nuclear con dos reactores, a once kilómetros al norte del pueblo.

La instalación se encuentra sobre un relieve silíceo, dispuesto en bandas paralelas entre sí, que permite un aprovechamiento limitado, agroganadero, que, sin embargo, no está acompañado de otros sectores que, sin lugar a duda, habrían permitido el asentamiento de más población (Púa, 2013). Es una de las comarcas más afectadas por el éxodo rural y la emigración de la segunda mitad del siglo pasado, con escasísima población joven, lo que hace que la disponibilidad de servicios sea mínima. En definitiva, una comarca subdesarrollada (Prieto y García Dory, 2018).

Las obras de la central (figura 6) comenzaron en 1975 y llegaron a tener hasta cuatro mil trabajadores a la vez en la misma. Valdecaballeros vivió su propia metamorfosis urbanística. Sin embargo, la moratoria nuclear de 1986, con el primer reactor a punto de empezar a funcionar, supuso el inicio de incertidumbres que llevaron a la parada de la obra en 1991. En 2001 se desmanteló la maquinaria de la central, a excepción de los transformadores, utilizados para dos parques solares creados años después, que no cumplen las expectativas de desarrollo para una comarca tan necesitada. En definitiva, a Valdecaballeros "le mataron el futuro" sin pensar en alternativas creíbles (Tertsch, 2001; Naredo, 2017).

\subsection{La Haba: Ias minas que mataron a un pueblo}

Un ejemplo más trágico que el mencionado de Valdecaballeros, -dentro del conjunto de instalaciones del "Patrimonio Nuclear del Sur de España"-, es el de la localidad de La Haba, situada en el límite entre las comarcas pacenses de las Vegas Altas y La Serena. A este pequeño pueblo, que hoy día vive de la dehesa y sus productos -sobre todo la actividad ganadera-, junto con el éxodo rural y la emigración a Francia y Alemania, se le sumó la gran tragedia de una minería de uranio mal gestionada. Desde las primeras calicatas de 1953

16 Valdecaballeros, Talarrubias, Herrera del Duque y Castilblanco. 
al cierre de la mina a cielo abierto "Marilozana" (figura 7) y la planta "experimental" de ENUSA en 1991, fueron 38 años de una relativa "fiebre del uranio" en una comarca de amplia tradición minera. Explotadas en sistema de galerías desde 1962-63 las minas del Lobo y el Pedregal, con posterioridad se cometió el considerable error de abrir la mina "Marilozana" a cielo abierto, con el evidente riesgo radiológico. También hay fuentes que señalan que en una de las galerías de las antiguas minas del Lobo-concretamente en la "Lobo 7"- se enterró el reactor nuclear "JEN 1" de La Moncloa (Madrid) cuando sufrió el accidente en 1973.

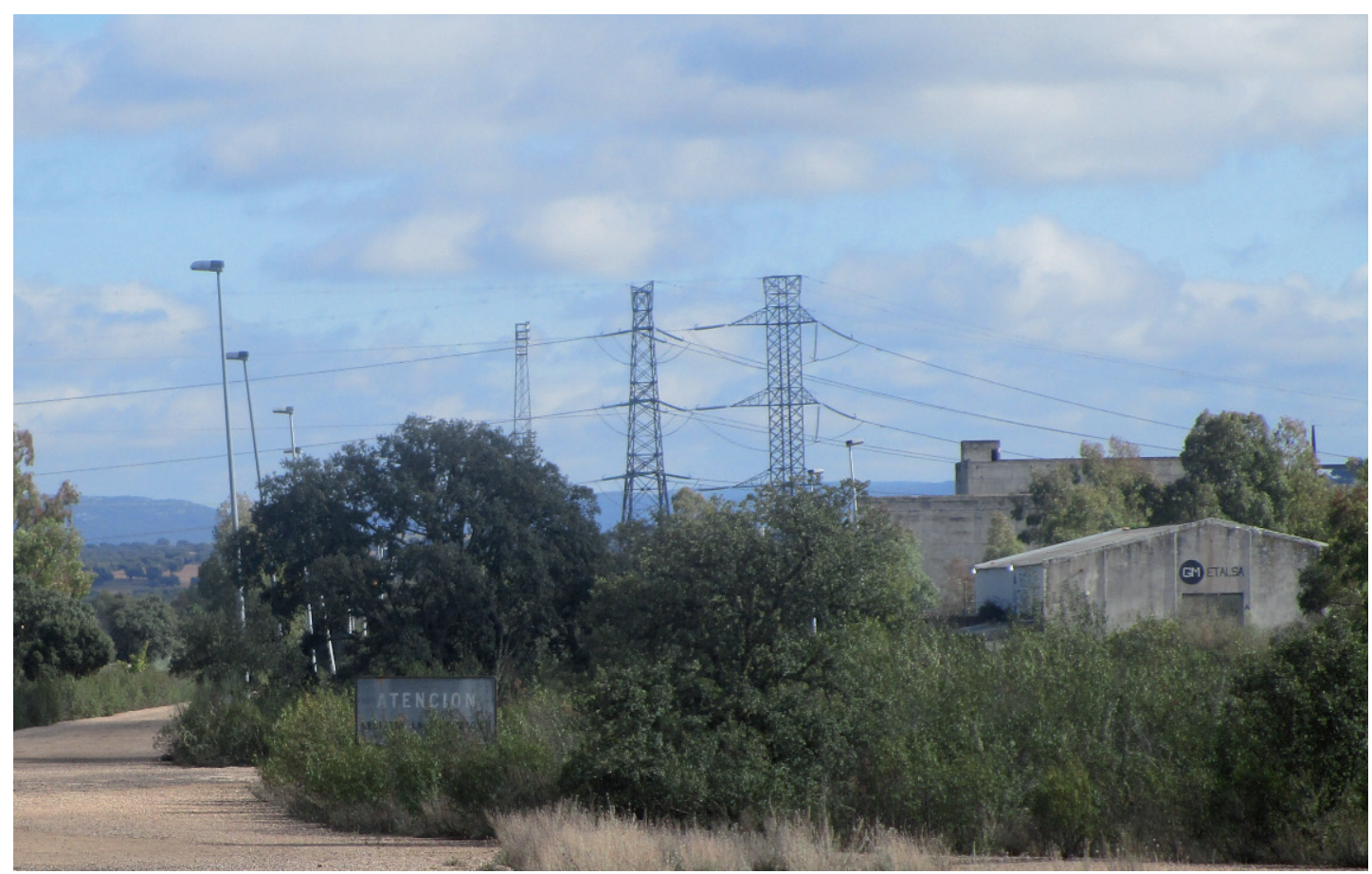

Figura 6. Estado de abandono actual de la antigua Central de Valdecaballeros. Fuente: Autor (Muñoz, 2018).

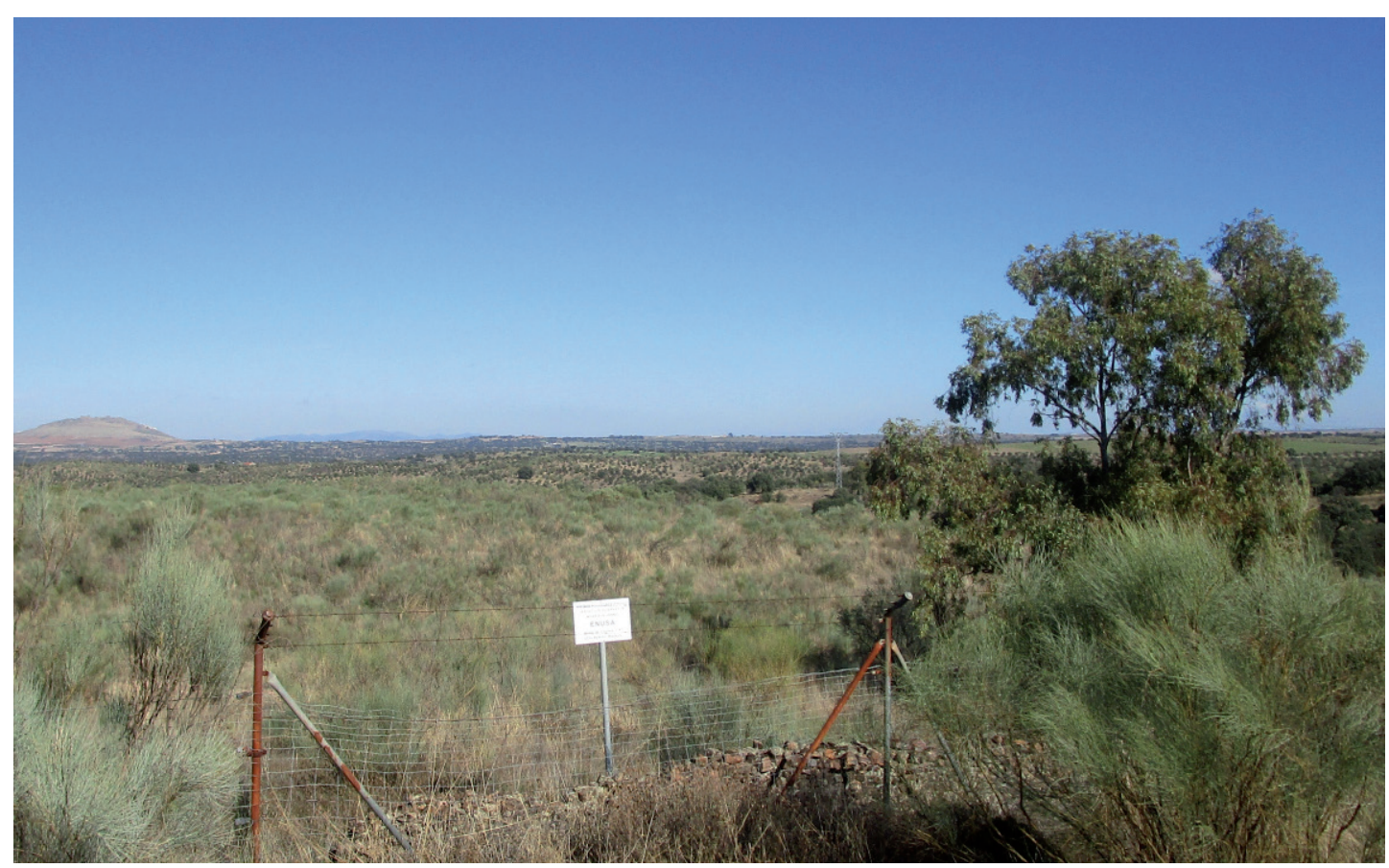

Figura 7. Imagen de la antigua mina Marilozana, una vez sellada. Fuente: Autor (Muñoz, 2020). 
Hasta 1975, el mineral de uranio se trasladó en camiones a Magacela, y desde allí, en tren, hasta la FUA "General Hernández Vidal" de Andújar. Del análisis de campo realizado, sobresale el hecho de que la población de La Haba es muy reacia a hablar "del uranio". Muchos jabeños consideran que "el uranio ha matado al pueblo". El análisis de los datos poblacionales consultados, en estadísticas y de forma directa17, muestra que un porcentaje cercano al $40 \%$ de la población ha fallecido joven, todos de enfermedades oncológicas, relacionadas con la exposición al uranio y la radiactividad. La Fábrica "experimental" de ENUSA en La Haba funcionó desde 1975 a 1991. Almacenó bidones radiactivos hasta 1993, cuando ya deberían haber concluido las labores de desmontaje, descontaminación y restauración paisajística del conjunto, la cual no se llevó a cabo hasta varios años más tarde, entre 1997 y 1998. Y, sin embargo, lo que ha permanecido en la memoria colectiva, cada vez más pequeña y mermada de los jabeños, ha sido su propia tragedia personal, con casi la mitad de los habitantes muertos por cánceres relacionados con la radiactividad. Pese a la rapidez de ENRESA en llevar a cabo las labores de desmantelamiento, descontaminación, sellado y vigilancia de las antiguas minas y fábrica de uranio, lo cierto es que la peor cara de la minería del uranio diezmó a este pequeño pueblo pacense. En definitiva, Valdecaballeros y La Haba son dos ejemplos de fracaso en la política y gestión "nuclear" en España: en la primera localidad se quedaron sin central nuclear y sin futuro; en la segunda, sin almacén y sin salud tras el final de la minería del uranio.

\section{DISCUSIÓN Y CONCLUSIONES}

En el presente estudio se ha puesto de manifiesto la evolución histórica reciente, la realidad actual y el valor del patrimonio nuclear del sur de España. Un conjunto de infraestructuras, equipamientos y paisajes que sufren una estigmatización por la peligrosidad asociada al uranio. En el análisis de las localizaciones del patrimonio nuclear sobresalen los aspectos siguientes:

- El estudio del caso doble de Andújar -minas en la sierra y FUA en sus afueras-, muestra resultados evidentes de lo señalado (estigmatización de un territorio) a partir del estudio de las minas y su trayectoria, y del análisis del tema tabú que representa la tragedia de la FUA, con sus consecuencias hasta nuestros días. Existen evidentes analogías entre las minas cardeñesas en torno a la Venta del Cerezo y las del entorno norte y noroccidental del Santuario de Nuestra Señora de la Cabeza, en la Sierra de Andújar.

- La evolución experimentada por El Cabril ha sido destacada en las últimas décadas. Esta localidad ha pasado de lugar de minas de uranio, mica y berilo a sede del Almacenamiento Centralizado de Residuos Radiactivos de muy baja a media actividad en España. Por su importancia y significación, tras algunos años relegado a un segundo plano por el truncado proyecto del ATC (2013-2020), El Cabril, es el principal activo de ENRESA/CIEMAT, y tiene aún nuevas posibilidades, con el desarrollo de actividades deportivas y ambientales.

- En Palomares se han analizado las labores llevadas a cabo a través del "Proyecto Indalo", destacando las iniciativas positivas que han permitido ir mejorando la percepción de esta localidad como área destacada de desarrollo agrario de vanguardia y turístico residencial, desde que ocurrió el accidente aéreo de efectos nucleares en 1966.

- Muy distinto es el caso de la provincia de Badajoz, que ha vivido dos realidades diametralmente opuestas. Por un lado, en Valdecaballeros se alumbró la gran esperanza de dejar atrás su multisecular escaso desarrollo con el proyecto de la central nuclear no desarrollada finalmente, lo que ha dado lugar a un futuro bastante incierto. Por otro, el caso de La Haba donde a la "fiebre del uranio" extraído de sus minas y transformado en su fábrica "experimental" de ENUSA siguió el cese de actividad en 1991 y posterior tragedia de las muertes motivadas por el contacto con distintos elementos radiactivos. 
De acuerdo con lo expuesto en el presente estudio, los dos mejores ejemplos de experimentación y de desarrollo de I+D+i son el Almacén Centralizado de Residuos de Muy Baja, Baja y Media Actividad de El Cabril y el conjunto de parcelas acotadas y sometidas a vigilancia radiológica en el entorno de Palomares y la Sierra Almagrera. Ambas zonas muestran la evolución y optimización de los conocimientos en tratamiento y gestión de residuos radiactivos (Alonso et al., 1989).

A modo de síntesis, se presentan las fortalezas y debilidades principales de los elementos del Patrimonio Nuclear del sur de España analizados en el presente estudio (tabla 2).

Tabla 2. Fortalezas y debilidades de los elementos del Patrimonio Nuclear del Sur de España.

\begin{tabular}{|l|l|l|}
\hline \multicolumn{1}{|c|}{ Lugar } & \multicolumn{1}{|c|}{ Fortalezas } & \multicolumn{1}{c|}{ Debilidades } \\
\hline Andújar: minas y FUA & $\begin{array}{l}\text { Minas: Parque Natural. } \\
\text { FUA: Localización. }\end{array}$ & $\begin{array}{l}\text { Minas: Despoblación. } \\
\text { FUA: Medio físico. }\end{array}$ \\
\hline Cardeña. & Parque Natural. & $\begin{array}{l}\text { Despoblación que impide desarrollar } \\
\text { proyectos. }\end{array}$ \\
\hline El Cabril & Excelente infraestructura de I+D+i & $\begin{array}{l}\text { Despoblación y distancia de núcleos } \\
\text { de población. }\end{array}$ \\
\hline Palomares & $\begin{array}{l}\text { Cercanía a la costa y a núcleos de } \\
\text { población importantes. Buenas } \\
\text { condiciones climáticas para el turismo } \\
\text { yla agricultura }\end{array}$ & $\begin{array}{l}\text { Variaciones en la cantidad de radiación } \\
\text { ("pluma”). }\end{array}$ \\
\hline Valdecaballeros & Gran disponibilidad de suelo y aguas. & $\begin{array}{l}\text { lu estándares propios de una región } \\
\text { escasamente desarrollada. }\end{array}$ \\
\hline La Haba & ZePA, buena situación intercomarcal. & $\begin{array}{l}\text { Despoblación, así como extrema } \\
\text { dependencia de Don Benito-Villanueva } \\
\text { de la Serena. }\end{array}$ \\
\hline
\end{tabular}

Fuente: Elaboración propia.

Las administraciones (estatal y regionales) han hecho escasas propuestas de actuación para poner en valor este innegable patrimonio y revertir la carga onerosa que ha supuesto para estas localidades, fomentando una diversificación más que necesaria en sus, en general, magras posibilidades de desarrollo sostenible. En efecto, a nivel oficial, la ausencia de iniciativas para la promoción del Patrimonio Nuclear del Sur de España, que, como tales reconozcan la condición de esas infraestructuras, es palmaria. Basta recorrer las localidades y lograr entablar conversación alusiva al pasado y patrimonio nuclear de las mismas para sacar sus conclusiones: más allá de las labores de vigilancia de ENRESA, no hay prácticamente nada. Se podría haber hecho más para la promoción socioeconómica de estos espacios. De ahí la necesidad de proponer actuaciones.

Considerando el hándicap de la radiactividad, cuya vigilancia debe ser constante, en algunas de las localidades afectas al Patrimonio Nuclear del Sur de España, sí se podrían emprender infraestructuras similares a las ya existentes en Almadén (Cañizares, 2011 a y b, 2013), así como el fomento de las ya existentes como las creadas en Palomares, que están sin desarrollar en los últimos años, por distintos motivos.

La investigación acometida en este trabajo es novedosa por el conjunto de instalaciones que aborda: antiguas minas de uranio, fábricas de refinado de uranio desmanteladas, un almacén de residuos radiactivos y una central nuclear "non nata"; todo ello con el método de trabajo del análisis geográfico.

Por último, como resultado del análisis-diagnóstico realizado en el presente trabajo, se presentan una serie de propuestas para el fomento y valorización del Patrimonio Nuclear del Sur de España, se incluye la siguiente tabla pormenorizando los distintos elementos que lo integran, así como las posibles opciones para su dinamización como recursos para la reactivación turística o, en general, socioeconómica de las áreas de estudio (tabla 3). 
Tabla 3. Propuestas de actuación en las instalaciones del patrimonio nuclear del sur de España, analizadas en el presente estudio.

\begin{tabular}{|c|c|c|}
\hline LOCALIDAD & ELEMENTO DEL PATRIMONIO NUCLEAR & PROPUESTAS de ACTUACIÓN \\
\hline Andújar & Antiguas minas y FUA ("la Escombrera”). & $\begin{array}{l}\text {-Modificación del sellado de la FUA siempre que } \\
\text { no implique más problemas radiológicos con } \\
\text { idea de potenciar proyectos ya existentes. } \\
\text {-Recurso didáctico para la enseñanza }\end{array}$ \\
\hline Cardeña & Antiguas minas de uranio & $\begin{array}{l}\text {-Conclusión de proyectos a medio desarrollar } \\
\text { para la valoración de la localidad. } \\
\text {-Valorización del rico entorno natural e } \\
\text { integración de la mina como elemento turístico } \\
\text { visitable }\end{array}$ \\
\hline El Cabril & $\begin{array}{l}\text { Antiguas minas de uranio y } \\
\text { Almacenamiento de RRNN de ENRESA }\end{array}$ & $\begin{array}{l}\text { - Creación de un Centro de Interpretación } \\
\text { adecuado al nivel de las instalaciones. } \\
\text {-Potenciación de las actividades de investigación } \\
\text { e innovación en el propio centro. }\end{array}$ \\
\hline Palomares & $\begin{array}{l}\text { Parcelas afectadas por el accidente aéreo- } \\
\text { nuclear de } 1966 .\end{array}$ & $\begin{array}{l}\text {-Vigilancia y adecuación de las parcelas afectadas } \\
\text { a sus posibles utilidades. } \\
\text {-Recurso didáctico para la enseñanza }\end{array}$ \\
\hline Valdecaballeros & Central nuclear "non nata" & $\begin{array}{l}\text {-Necesidad de un plan de promoción económica } \\
\text { de la localidad. } \\
\text {-Promoción turística de la Reserva de la Biosfera } \\
\text { de La Siberia } \\
\text {-Recurso didáctico para la enseñanza }\end{array}$ \\
\hline La Haba & $\begin{array}{l}\text { Antiguas minas de uranio y fábrica de } \\
\text { combustible nuclear desmantelada. }\end{array}$ & $\begin{array}{l}\text {-Valorización del patrimonio monumental como } \\
\text { elemento turístico. } \\
\text {-Recurso didáctico para la enseñanza }\end{array}$ \\
\hline
\end{tabular}

Fuente: Elaboración propia.

Son iniciativas y propuestas que se consideran necesarias para poner en valor el patrimonio nuclear del sur de España, relacionadas con la promoción turística y la educación. Por su parte, la combinación entre desarrollo sostenible y energía nuclear es posible, siempre y cuando los procesos sean llevados a cabo con las adecuadas condiciones de seguridad y protección para evitar fugas radiactivas, es posible. A corto y medio plazo, la energía nuclear va a seguir siendo una pieza fundamental del mix energético de nuestro país, en el contexto de cambio climático y necesidad de reducción de emisiones.

La investigación, como se ha señalado, analiza instalaciones que no han sido tratadas en trabajos anteriores, desde la disciplina geográfica: antiguas minas de uranio, fábricas de refinado de uranio desmanteladas, un almacén de residuos radiactivos y una central nuclear que finalmente no se llevó a cabo. Se pueden encontrar enfoques aproximados en algunas investigaciones realizadas sobre valorización y propuestas hechas con el patrimonio minero e industrial de Almadén (Cañizares, 2011 a y b, 2013, 2020), la Sierra Almagrera (Menéndez, 2016) y Riotinto (Pérez et al., 2016). Con ellas comparte la necesidad de integrar estos espacios del patrimonio nuclear en los circuitos de las visitas turísticas y de la educación ambiental en las localizaciones estudiadas. No podemos olvidar el interesante trabajo de Espejo Marín (2002), que en su momento señaló la necesidad de profundizar en el estudio general de la "geografía de la energía nuclear en España", que es un esfuerzo todavía sin realizar en España y con el que este trabajo ha intentado profundizar a partir del estudio de casos locales destacados. En otros países, como Francia, el concepto de "patrimonio nuclear", así como su estudio, ha merecido artículos iniciales a partir de 2020 (Mathieu, 2020; Wakim, 2021), si bien con un carácter más de reportaje que de análisis patrimonial como aborda este trabajo.

Como ha ocurrido en otros lugares de nuestro país, en los que se ha puesto en valor equipamientos relacionados con la actividad minera desarrollada en épocas pasadas, las localidades del sur de España que integran el patrimonio nuclear, presentan potencialidad para llevar a cabo acciones que fomenten el 
desarrollo local y comarcal. En este caso, además, se unen paisajes "de lo nuclear" que tienen belleza y potencialidad como recurso didáctico y de ocio. Es importante conocer la evolución histórica, la realidad actual y las propuestas de futuro de los lugares del patrimonio nuclear del sur de España. Con el estudio abordado, desde la perspectiva geográfica, de los distintos lugares que lo integran, de sus características, de sus fortalezas, debilidades y posibilidades de cara al desarrollo futuro de sus entornos territoriales, se ha pretendido la visibilización de una realidad que, sin duda, merece aproximaciones más detalladas desde las disciplinas histórica y sociológica. El presente trabajo pretende abrir nuevas vías de análisis de un patrimonio, poco valorado en nuestro país, debido a la percepción negativa que subyace a lo nuclear. Porque el desconocimiento de la realidad territorial de estas localidades surgidas o desarrolladas en relación con los recursos, objetos o con proyectos de generación de energía nuclear conduce a conclusiones tendenciosas que solo la investigación científica puede aclarar.

\section{Agradecimientos}

A quienes creyeron en las posibilidades de un trabajo como éste. Y, de modo particular, a los miembros del Tribunal ante el que se defendió la Tesis Doctoral que dio lugar a este y otros artículos, por sus notables aportaciones.

\section{Declaración responsable y conflicto de intereses}

Los autores declaran que no existe ningún conflicto de interés con relación a la publicación de este artículo. Los dos autores han participado en la organización de contenidos, en la selección de la metodología empleada, en la revisión bibliográfica y han revisado y corregido las diferentes versiones del manuscrito. La idea original de la investigación y el trabajo de campo ha sido realizado por Juan Antonio Muñoz Castillo.

\section{REFERENCIAS}

Alonso, L., Iñarra, I., Cancio, D \& del Potro, R. (1989). Residuos radiactivos. Ministerio de Obras Públicas y Transportes. Álvarez de Toledo. L.I. (2002). Palomares. Memoria.UNED.

Bezat, J.M. (2021, 19 de abril). Le nucléaire peut-il être considéré comme un investissement durable, au même titre que les énergies renouveables? Le Monde. https://www.lemonde.fr/idees/article/2021/04/19/nucleaire-la-guerre-fait-rage-a-l-approche-d-une-decision-de-bruxelles-sur-les-technologies-labellisees-vertes_6077235_3232.html

Cañizares Ruiz, Ma C. (2011a). Patrimonio, parques mineros y turismo en España. Cuadernos de Turismo, 27, $133-154$. https://doi.org/10.6018/turismo

Cañizares Ruíz, Ma C. (2011b). Protección y defensa del patrimonio minero en España. Scripta Nova, 15, 348-386. https:// raco.cat/index.php/ScriptaNova/article/view/241319

Cañizares Ruiz, Ma C. (2013). Patrimonio, minería y rutas en el Valle de Alcudia y Sierra Madrona (Ciudad Real). Estudios Geográficos, 74 (275), 409-437. https://doi.org/10.3989/estgeogr.201315

Cañizares Ruiz, M ${ }^{a}$ C. (2020). Visibilidad del patrimonio minero en algunos geoparques españoles. Documents d́ Análisi Geográfica, 66 (1),109-131. https://doi.org/10.5565/rev/dag.556

Echagüe Méndez de Vigo, G. (ed.) (2000). Residuos radiactivos y su percepción pública. Ilustre Colegio de Físicos.

Enresa (1986-2019). Planes de I+D y Planes de $I+d+i$. Documentos.

Espejo Marín, C. (2001). El sector eléctrico español en la prensa escrita. Cuadernos Geográficos de la Universidad de Granada, 31(S), 203-220. https://doi.org/10.30827/cuadgeo.v31i0.1949

Espejo Marín, C. (2002). La producción de electricidad de origen nuclear en España. Boletín de la Asociación de Geógrafos Españoles, 33, 65-77. https://bage.age-geografia.es/ojs/index.php/bage/article/view/415

Espejo Marín, C. (2002). L'energie electronucleaire en I’Espagne. Annales de Geographie, 625, 319-328. https://doi. org/10.3406/geo.2002.2088 
Espejo Marín, C. \& Capel Molina, J.J. (2007). El gas en la producción de electricidad en España. Nimbus. Revista de Climatología, Meteorología y Paisaje, 19-20, 71-98.

Fernández-Arias, P., Cuevas, A. \& Vergara, D. (2021). Controversia nuclear en España: la central nuclear de Lemóniz. Revista Iberoamericana de Ciencia, Tecnología y Sociedad-CTS, 16(46), 199-218

Gonzalvo Salas, C., Zuaznabar Uzkudun, G. \& Ródenas García, J.F. (2018). Centrales Nucleares y Patrimonio: El caso de la central nuclear de Vandellós-I(Tarragona). E-rph: Revista electrónica de Patrimonio Histórico, 23, 1-23. https://doi. org/10.30827/e-rph.v0i23.17862

Herrera Plaza, J. (2019). Silencio y deslealtades: el accidente de Palomares desde la Guerra Fría hasta hoy. Laertes.

López Ontiveros, A. (coord.) (1998). Geografía de Andalucía. Ariel.

Mathieu, B. (2020, 15 de julio). Patrimoine nucléaire: les "papys" entrent en résistance por sauver la "fierté nationale".

Ĺ Express. https://lexpansion.lexpress.fr/actualite-economique/patrimoine-nucleaire-les-papys-entrent-en-resistance-pour-sauver-la-fierte-nationale_2130400.html.

Menéndez Suárez, C. (2016). La minería en la Sierra de Almagrera (Almería) y el ferrocarril minero del barranco Jaroso. De re metallica, 27, 1-19.

Mihm, A. (2019, 11 de mayo). Das ungeliebte Erbe des Atomstroms. Frankfurter Allgemeine. https://www.faz.net/aktuell/ wirtschaft/klima-nachhaltigkeit/wohin-mit-dem-atommuell-das-ungeliebte-erbe-des-atomstroms-16480139.html (Consultado, agosto 2020).

Muñoz Castillo, J.A. (2010). El Cabril. Estudio Geográfico [Memoria de Licenciatura, Universidad de Córdoba].

Muñoz Castillo, J.A. (2012). Antonio Carbonell, mucho más que el creador de El Cabril. Séneca Digital. Córdoba.

Muñoz Castillo, J.A. (2013). El bosque-galería de El Cabril: un paisaje entre lo natural y lo antropizado. Iberian.

Muñoz Castillo, J.A. (2016). Patrimonio Nuclear del Sur de España. Un objeto necesitado de estudio. Argentaria, $14,94-98$.

Muñoz Castillo, J.A. (2017). La Fábrica de Uranio de Andújar: hablan los trabajadores. Argentaria, 17, 58-64.

Muñoz Castillo, J.A. (2020). Patrimonio Nuclear del Sur de España. Un estudio geográfico [Tesis Doctoral, Universidad de Alicante].

Muñoz Castillo, J.A. (2021). Patrimonio Nuclear del Sur de España. Unas conclusiones sobre el caso doble de Andújar: las minas y la Fábrica de Uranio de Andújar "General Hernández Vidal". Argentaria, 24,1-8.

Naredo, J.M. (2017). Extremadura saqueada en perspectivas. Encrucijadas, 17.

Perarnau Perramón, M. (coord.) (1966). Fábrica de Uranio de Andújar General Hernández Vidal. JEN.

Pérez Macías, J.A., Delgado Domínguez, A., Pérez López, J.M. \& García Delgado, F.J. (eds.) (2016). Río Tinto. Historia, patrimonio minero y turismo cultural. Fundación Río Tinto. Publicaciones de la Universidad de Huelva.

Prieto, D. \& García-Dory, F. (2018). Dominación y (neo)extractivismo: 40 años de "Extremadura saqueada". Matadero, col. "Campo adentro".

Púa, C. (2013). Extremadura: la Siberia, sus personajes y sus costumbres. Castilblanco, Ed. del Autor.

Reporterre, le quotidien de I ecologie. Varios números. https://reporterre.net

Romero Silva, J.C. (2019). La minería del distrito Marbella-Ojén (Serranía de Ronda): la razón de la Málaga industrial del primer tercio del siglo XIX De re metallica, 32, 47-60.

Tertsch, H. (2001, 7 de enero). Valdecaballeros, la central del nunca jamás. Diario El País. https://elpais.com/diario/2001/01/07/sociedad/978822004_850215.html

Utrera Cardeñas, P. (2009). El sueño de Franco, la pesadilla de Andújar. Los damnificados de la FUA. Plaza Vieja.

Velarde, G. \& Carpintero, N. (2016). Proyecto Islero: cuando España pudo desarrollar armas nucleares, Córdoba. Guadalmazán (grupo Almuzara).

Wakim, N. (2021, 16 de febrero). Montebourg, Accoyer et Chevènement unis pour la défense du patrimoine nucléaire français. Le Monde. https://www.lemonde.fr/economie/article/2021/02/15/montebourg-accoyer-et-chevenement-unis-pour-la-defense-du-patrimoine-nucleaire-francais_6070042_3234.html 